\title{
The Impact Of Repeated Data Breach Events On Organisations' Market Value
}

\author{
Daniel Schatz * and Rabih Bashroush ${ }^{\S}$ \\ * Thomson Reuters, London, UK. \\ Email: daniel.schatz@thomsonreuters.com \\ $\S$ University of East London, London, UK. \\ Email: r.bashroush@qub.ac.uk
}

\begin{abstract}
Purpose - In this study, we examined the influence of one or more information security breaches on an organization's stock market value as a way to benchmark the wider economic impact of such events.

Design/Methodology/approach - We used an event studies based approach where a measure of the event's economic impact can be constructed using security prices observed over a relatively short period of time.

Findings - Based on the results, we argue that although no strong conclusions could be made given the current data constraints, there was enough evidence to show that such correlation exists, especially for recurring security breaches.

Research limitations/implications - One of the main limitations of this study was the quantity and quality of published data on security breaches, as organizations tend not to share this information.

Practical implications - One of the challenges in information security management is assessing the wider economic impact of security breaches. Subsequently, this helps drive investment decisions on security programmes that are usually seen as cost rather than moneymaking initiatives.

Originality/value - We envisage that as more breach event data become more widely available due to compliance and regulatory changes, this approach has the potential to emerge as an important tool for information security managers to help support investment decisions.
\end{abstract}

Keywords Information Security, Event Based Analysis, Information Security Breaches Paper type Research paper 


\section{Introduction and related work}

Protection of digital information has been and continues to be a growing concern across all areas of business. Cybersecurity-related attacks are not only increasing in number and diversity, but also becoming more damaging and disruptive (National Institute of Standards and Technology, 2012). Despite increasing efforts to implement security controls in an attempt to prevent information security breaches, we continue to see news of organisations suffering from incidents (Passeri, 2013). This study investigates the impact of security events on the stock price of publicly listed companies. As described by Cutler et al. (1989) asset prices are generally attributable to changes in the fundamental value of the asset and as such react to announcements about corporate control, regulatory policy and macroeconomic conditions that plausibly affect fundamentals. Under the assumption of an efficient market (Fama, 1970), and the rejection of the random walk hypothesis (Lo and MacKinlay, 1988), we assume that new information relevant to a traded equity becoming public knowledge has the potential to affect the market value of that equity (deBondt and Thaler, 1985, Fama et al., 1969). This assumption has been the focus of various studies as discussed below.

In this work, we particularly examine the impact of publicly reported information security incidents on the share price of organisations. Organisations store an ever increasing amount of information about their business partners, employees or customers and hold the responsibility to protect this data. At all stages of the data lifecycle - data collection, data use, data storage, data retention, data destruction - it must be ensured that sufficient protection is provided against unauthorized use (Grama, 2010). Yet we continue to see instances where this duty of care appears to fail as data is disclosed to unauthorized parties. While data breach is a widely discussed topic, there is little guidance in literature on the definition of a data breach. We are following the International Standards Organisation (2014) which defines a data breach to be a compromise of security that leads to the accidental or unlawful destruction, loss, alteration, unauthorized disclosure of, or access to protected data transmitted, stored or otherwise processed. In their cost of data breach study the Ponemon Institute (2014) finds a significantly higher monetary impact for those breaches caused by malicious or criminal attacks. Consequently, in our research we focus on information security breaches caused by external malicious or criminal attacks.

As it is notoriously difficult to obtain any information on direct or indirect cost resulting from an information security breach, a study of the market reaction to such an incident is the best proxy for economic consequences. A common approach for this is the use of event studies where a measure of the event's economic impact can be constructed using security prices observed over a relatively short period of time (MacKinlay, 1997). At the core of an event study is the measurement of an abnormal stock return during the observation window. The observation window typically includes a time period leading up to the observed event, the event itself, as well as a post event period. The application of event studies in this form is well documented in academic research covering corporate events like earning announcements, stock splits (Fama et al., 1969) and mergers and acquisitions (Duso et al., 2010).

Previous studies leveraging event study methodology to investigate the effect of information security incident events on market value include work by Kannan et al. (2007), Yayla and Hu (2011), Cavusoglu et al. (2004), Campbell et al. (2003), Gatzlaff and McCullough (2010) and Garg et al. (2003). Wang et al. (2007) take a different approach and apply event study 
methodology to financial reporting data rather than public breach announcements. Telang and Wattal (2007) apply the methodology to a precursory event, announcement of software vulnerabilities, to observe the effect on stakeholders in this context. Andoh-Baidoo et al. (2010) extend event study results with decision tree induction to further examine the relationship between independent variables.

The following section highlights the research methodology used. Section 3 presents the research questions and hypothesis as well as the dataset used for validation. In section 4, the experiment conducted is described. Results are then discussed in section 5. The study limitations and potential threats to validity are covered in section 6 . And finally, conclusions are drawn in section 7.

\section{Research methodology}

Measuring or even estimating the true impact of information security breach events on the economic wellbeing of organisations is a difficult problem to solve. Industry reports like the Ponemon study (Ponemon Institute, 2014) aim to approximate the cost taking various factors like expense outlays for detection, escalation, notification, after-the-fact (ex-post) response, analysis of the economic impact of lost or diminished customer trust and confidence as measured by customer turnover or churn, into consideration but also acknowledge limitations of their approach. A possible alternative developed in the field of economics is the event study methodology. Event study is a statistical approach relying on the assumption of efficient markets to identify abnormal returns resulting from an event. MacKinlay (1997) explains that the usefulness of such a study stems from the fact that, given rationality in the marketplace, the effects of an event will be reflected immediately in security prices. Although this relies on the assumption of an efficient or rational market, which is not without problems itself (Malkiel, 2003), the results produced are perceived to be a fair (non biased) 'cause - effect' approximation.

At the core of an event study is an asset measureable over time (e.g. valuation of equity) and an event that is suspected to affect the value of that asset. Practical issues like data availability for a chosen asset should be considered early on. Obtaining the necessary dataset to complete the study may be difficult (where data is not publicly accessible) or not feasible due to cost or resource constraints. To conduct a study, the time of the event must be defined and a time window constructed around it. This window includes a period leading up to the event (estimation window) to baseline expected or normal returns, a narrow event window, and a post event window to measure the impact. The selection of the event window needs to strike a balance between being too narrow, potentially missing leading or trailing reaction, and too broad, risking deluding results through confounding events and other long term event study issues (Kothari and Warner, 2004). With the basic requirements in place, the normal returns for the asset can be calculated throughout the estimation window followed by a calculation of the potential abnormal returns in the event window. Two common approaches for this are the constant mean return model and the market model. A detailed description of the model intricacies and varieties is out of scope for this paper. Further details on this can be found in Brown and Warner (1985) and Kothari and Warner (2004).

\section{Hypothesis development and approach}


As mentioned in section 1, event study methodology has previously been applied to study the economic impact of information security events. The amount of available research remains limited compared to other areas, particularly considering the increasing interest in and prevalence of publicly reported information security breaches. This study aims to extend the existing research by investigating stock price reaction of organisations that have been affected by information security events more than once. The study seeks to answer two main research questions:

- RQ1: Do publicly reported information security breaches impact stock prices of affected organisations?

- RQ2: Is there a difference in stock price impact, compared to a previous breach of that organisation, if organisations experience a subsequent information security breach event?

These questions are formulated in two hypotheses:

$\mathrm{H}_{1}$ - Publicly reported information security breaches do not lead to abnormal returns for the stock price of the affected organisation.

$\mathrm{H}_{2}$ - There is no difference in stock price reaction between the first measured breach event and a subsequent breach event for an organisation

With the help of RQ2 we attempt to get an understanding of the reaction of market participants if the same organisation is breached repeatedly. We try to clarify whether investors penalise organisations in such cases (i.e. failure to provide tangible improvements on information security), show indifferent behaviour or even react positively.

To answer the outlined research questions, the study needs to be set up meeting several conditions. Figure 1 provides a high level view of the approach and the workflow followed. 


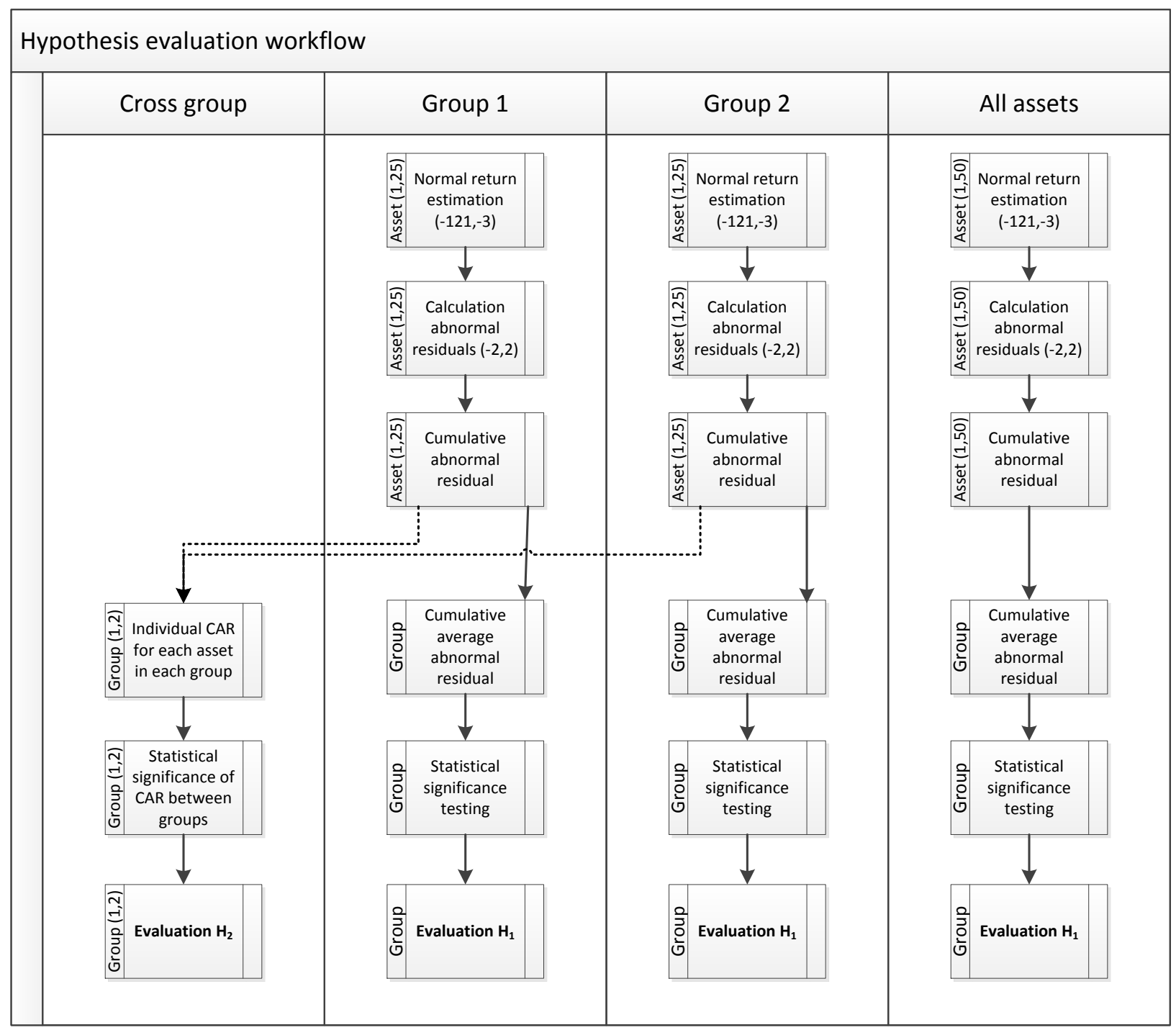

Figure 1 - Approach and workflow

As shown above, the normal returns for each asset (stock) in each group are estimated based on the corresponding estimation window ( -121 to -3 days). Then, abnormal returns are calculated based on the event window for each asset ( -2 to +2 days). This results in a cumulative abnormal residual for each asset from which a cumulative average abnormal residual is calculated. Statistical significance tests are then applied to evaluate results against the stated hypothesis in the workflow (Group 1, Group 2 and All assets). Cross group calculations are conducted based on the individual cumulative abnormal returns for Group 1 and Group 2 which is discussed in section 6 . 


\subsection{Event data sample selection}

For this study, the requirements on the underlying event data set are rather high as a simple selection of organisations that suffered from a security breach is insufficient to provide an answer on $\mathrm{H}_{2}$. Data sets available from the Open Security Foundation's DatalossDB ${ }^{\mathrm{i}}$ and the Privacy Rights Clearinghouse ${ }^{\mathrm{ii}}$ have been considered. While the data available from DatalossDB is likely the most exhaustive repository available, its use for academic research is ambiguous due to copyright issues (Widup, 2012). On the other hand, the Privacy Rights Clearinghouse (PRC) data poses no such issue but is not as exhaustive and almost exclusively focused on US based entities. However, this limitation was not an issue for our work, and accordingly, the PRC dataset was chosen for our experiment.

The PRC database provides information on data breaches reported starting 2005 and up to date. These are categorized under various verticals such as: Business, Educational, Government and Military, Healthcare and Non-profit Organisations. Breach information is categorized under: Unintended disclosure, Hacking or malware, Payment Card Fraud, Insider, Physical loss, Portable device, Stationary devices and Unknown or other. For this study, the full dataset for the Business category (i.e. excluding EDU, GOV, MED and NGO) was retrieved. The dataset was reviewed for repeat breaches and filtered for events classified as 'HACK', 'DISC' or 'UNKN'. Other categories like 'CARD', 'STAT' or 'PHYS' were not considered due to the focus of this study being on information security breach events. The remaining 180 events were screened considering the following criteria:

- Public company listed at a stock exchange

- Price data available ${ }^{\mathrm{iii}}$

- Not acquired, merged or ceased trading

- No overlapping event windows for repeated breaches or duplicate events

- No notable confounding events close to event window ${ }^{\text {iv }}$

\begin{tabular}{lc}
\hline Selection steps & Records \\
\hline Total events retrieved from PRC & 1490 \\
Events for organisations affected twice or more & 409 \\
Events categorised as DISC, HACK, UNKN & 180 \\
Events passing suitability criteria & 50 \\
\hline \multicolumn{2}{c}{ Table 1 - Privacy Rights Clearinghouse data set }
\end{tabular}

After applying the selection criteria, 25 organisations were filtered, each with two breach events. The breach events do not necessarily represent the first breach event for an organisation that ever occurred and not necessarily the second or latest. This is due to the limitation of the data available in the PRC database. The data sample for this study thus consists of a breach event that happened at an earlier stage and another that happened at a later stage in the trading history of an organisation. 


\subsection{Price data selection}

To calculate potential abnormal returns the stock price time series for each organisation in the event pool was required. Various sources for such information are available ranging from free services like Google Finance, Yahoo Finance to commercial providers like Bloomberg, Center for Research in Securities Prices (CRSP) and Thomson Reuters. Many previous studies prefer data provided by the Center for Research in Securities Prices (CRSP) whereas this study is using Thomson Reuters Datastream which is of at least comparable quality (Ince and Porter, 2006).

To retrieve relevant time series data, the correct identifier for the equities in scope, as well as an appropriate time window was needed. The time window for price data was defined as 121 days before the event date and 30 days after. This time frame was chosen based on previous similar studies examining short horizon event effects utilising an estimation window (Dyckman et al., 1984, Patell, 1976).

This approach maximizes the estimation time window while avoiding overlap with an information security breach event affecting the same asset earlier in time. Due to the setup of this study, an extension of the pre event time window was not possible without introducing overlapping estimation windows between events.

To conduct analysis of the events following the 'Market Model' time series, data for Standards \& Poors 500 Composite (S\&PCOMP) was retrieved. The S\&P 500 was selected as it is listed as the local market index (INDXL) for the majority of the assets in scope.

\subsection{Data preparation and analysis method}

Before conducting the analysis, sanity checks and some formatting had to be conducted over the collected data. Two data issues were investigated. The first is when events fell on non-trading days. The second is gaps (missing information) in the pricing data. Once checks were completed (using manual and too support), the raw data was formatted as Comma Separated Values (CSV) following a predefined layout.

To analyse the data, a standard Market Model methodology was chosen as per Dyckman et al. (1984). In that work, it was shown that the Market Model offers more powerful tests than the Mean-Adjusted Returns Model and the Market-Adjusted Returns Model in detecting abnormal performance. The Market Model is defined as shown in equation (1).

$$
\mathrm{R}_{\mathrm{i}, \tau}=\alpha_{\mathrm{i}}+\beta_{\mathrm{i}} \mathrm{R}_{\mathrm{M}, \tau}+\varepsilon_{\mathrm{i}, \tau} \text { with } \mathrm{E}\left[\varepsilon_{\mathrm{i}, \tau}\right]=0 \text { and } \operatorname{VAR}\left[\varepsilon_{\mathrm{i}, \tau}\right]=\sigma_{\varepsilon_{\mathrm{i}}}^{2}
$$

Where $\mathrm{R}_{\mathrm{i}, \tau}$ and $\mathrm{R}_{\mathrm{M}, \tau}$ are defined as period returns for the asset and market respectively. Alpha $\left(\alpha_{\mathrm{i}}\right)$, beta $\left(\beta_{\mathrm{i}}\right)$, variance $\left(\sigma_{\varepsilon_{\mathrm{i}}}^{2}\right)$ and prediction error $\left(\varepsilon_{\mathrm{i}, \mathrm{r}}\right)$ follow MacKinlay (1997).

For this study, Ordinary Least Squares (OLS) was chosen as estimation procedure over Scholes and Williams (1977). This is based on results from Dyckman et al. (1984) that showed the Scholes-Williams method of estimating risk does not enhance the ability to detect abnormal performance using daily data. Brown and Warner (1985) further comment on a possible bias issue induced by OLS, that is, when bias in beta exists events do not necessarily imply misspecification. All calculations were done using simple return mode (versus continuously compounded - $\log$ return mode). 
The time windows of relevance were set as -121 to -3 days (estimation window) as explained in section 3.2 and -2 to 2 days (event window). We recognize that Dyckman et al. (1984) establish that extension of the event window has a disproportionally negative effect on the models ability to identify impact. However, an event window of 5 days $(-2,-1,0,1,2)$ was chosen to account for any uncertainty around the event date. The uncertainty could emerge from many factors including the fact that security breach event dates are difficult to precisely pinpoint due to factors such as news dispersion and the speed of adjustment to the information revealed. This type of information typically follows a dispersion process starting with limited coverage (e.g. information security specific press) followed by wider coverage in technology outlets before it breaks to major news media outlets.

\section{Experiment}

As outlined in section 3.1, the dataset covers 25 organisations with two associated security breach events each. The overall set of 50 events was separated in two groups where Group 1 contained the earlier event of each pair and Group 2 the later event.

\begin{tabular}{|c|c|c|c|c|c|c|c|}
\hline Symbol & Organisation & Event date & Group & Symbol & Organisation & Event date & Group \\
\hline @AAPL & Apple & $9 / 4 / 2012$ & 1 & @AAPL & Apple & $2 / 19 / 2013$ & 2 \\
\hline @CMCSA & Comcast & $3 / 16 / 2009$ & 1 & @CMCSA & NBC Universal & $2 / 22 / 2013$ & 2 \\
\hline @DRIV & Digital River Inc. & $6 / 4 / 2010$ & 1 & @DRIV & Digital River Inc. & $12 / 22 / 2010$ & 2 \\
\hline @FOXA & Fox Entertainment Group & $7 / 23 / 2007$ & 1 & @FOXA & Fox Entertainment Group & $5 / 10 / 2011$ & 2 \\
\hline @GOOG & Google & $4 / 27 / 2007$ & 1 & @GOOG & Google & $3 / 7 / 2009$ & 2 \\
\hline$@ \mathrm{HKFI}$ & Hancock Fabrics & $11 / 23 / 2009$ & 1 & @HKFI & Hancock Fabrics & $3 / 5 / 2010$ & 2 \\
\hline @SRCE & 1st Source Bank & $6 / 10 / 2008$ & 1 & @SRCE & 1st Source Bank & $11 / 19 / 2010$ & 2 \\
\hline EXPN & Experian & $3 / 29 / 2007$ & 1 & EXPN & Experian & $4 / 5 / 2012$ & 2 \\
\hline H:ING & ING & $2 / 12 / 2010$ & 1 & $H: I N G$ & ING & $10 / 12 / 2010$ & 2 \\
\hline REL & LexisNexis & $7 / 13 / 2009$ & 1 & REL & LexisNexis & $6 / 8 / 2011$ & 2 \\
\hline $\mathrm{U}: \mathrm{C}$ & Citigroup & $9 / 21 / 2007$ & 1 & $\mathrm{U}: \mathrm{C}$ & Citigroup & $6 / 9 / 2011$ & 2 \\
\hline U:CFR & Frost Bank & $5 / 19 / 2006$ & 1 & U:CFR & Frost Bank & $11 / 7 / 2007$ & 2 \\
\hline U:CVS & CVS & $6 / 21 / 2005$ & 1 & U:CVS & CVS & $3 / 24 / 2012$ & 2 \\
\hline U:EFX & Equifax & $2 / 11 / 2010$ & 1 & U:EFX & Equifax & $10 / 10 / 2012$ & 2 \\
\hline U:HIG & Hartford & $9 / 12 / 2007$ & 1 & U:HIG & Hartford & $4 / 6 / 2011$ & 2 \\
\hline U:JPM & JP Morgan & $1 / 30 / 2011$ & 1 & U:JPM & JP Morgan & $3 / 28 / 2013$ & 2 \\
\hline U:LNC & Lincoln Financial Group & $7 / 26 / 2011$ & 1 & U:LNC & Lincoln Financial Group & $9 / 16 / 2012$ & 2 \\
\hline U:MWW & Monster.com & $8 / 23 / 2007$ & 1 & U:MWW & Monster.com & $1 / 23 / 2009$ & 2 \\
\hline U:NYT & The New York Times & $1 / 30 / 2013$ & 1 & U:NYT & The New York Times & $8 / 27 / 2013$ & 2 \\
\hline U:Idos & Leidos & $7 / 20 / 2007$ & 1 & U:Idos & Leidos & $1 / 18 / 2008$ & 2 \\
\hline U:T & AT\&T & $8 / 29 / 2006$ & 1 & $\mathrm{U}: \mathrm{T}$ & AT\&T & $6 / 9 / 2010$ & 2 \\
\hline U:TMUS & T-Mobile & $6 / 7 / 2009$ & 1 & U:TMUS & T-Mobile & $1 / 16 / 2012$ & 2 \\
\hline $\mathrm{U}: \mathrm{VZ}$ & Verizon & $8 / 12 / 2005$ & 1 & $\mathrm{U}: \mathrm{VZ}$ & Verizon & $8 / 25 / 2006$ & 2 \\
\hline U:WFC & Wells Fargo & $8 / 12 / 2008$ & 1 & U:WFC & Wells Fargo & $10 / 20 / 2011$ & 2 \\
\hline U:WYN & Wyndham Hotels \& Resorts & $2 / 16 / 2009$ & 1 & U:WYN & Wyndham Hotels \& Resorts & $2 / 28 / 2010$ & 2 \\
\hline
\end{tabular}


First, calculations were conducted over events in Group 1 to obtain the results on the earlier breach data. As shown in Figure 2, the cumulative average abnormal residuals (CAAR) exhibit a decrease of $2.38 \%$ over the defined event window with a positive to negative ratio of 7:18.

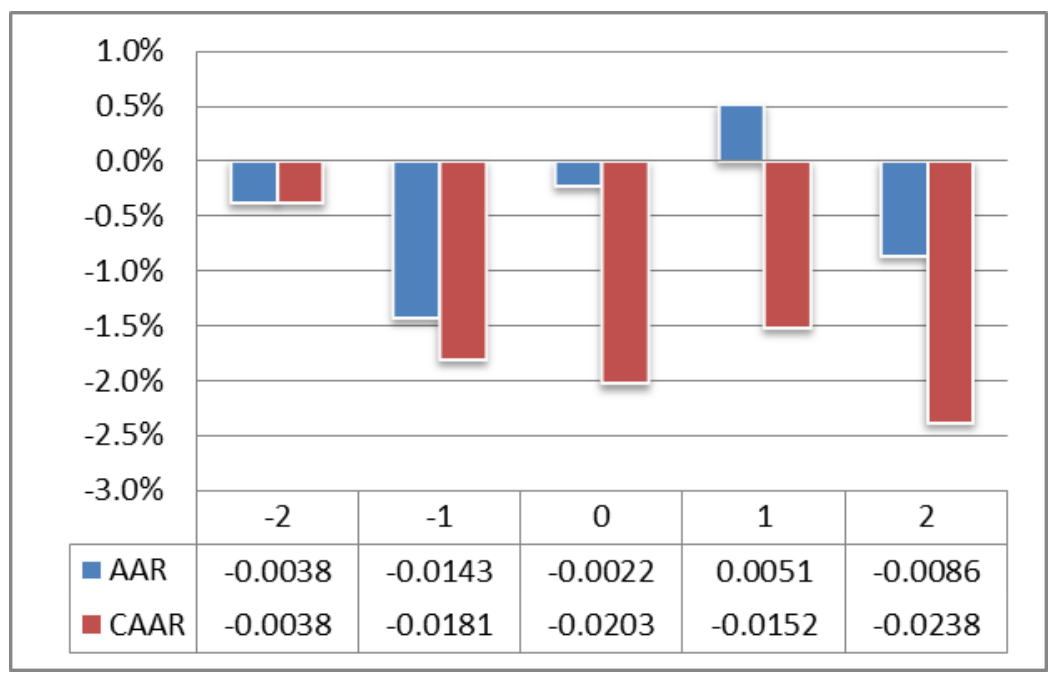

Figure 2 - Group 1 event impact

Based on the standardized cross-sectional test following the BMP approach (Boehmer et al., 1991), with adjustments as proposed by Kolari and Pynnönen (2010), it was shown that the statistical significance is $1 \%$. To verify the results of the parametric test, an additional nonparametric test was conducted. Following the observation by Cowan (1992) that the generalized sign test (GSIGN) becomes relatively more powerful as the length of the event window increases, the generalized sign test was selected over the rank approach as proposed by Corrado (1989). For Group 1, the GSIGN test does not confirm the parametric test results and merely approaches 5\% significance level as seen in Table 3.

\begin{tabular}{|lcrrrrr|}
\hline Event window & CAAR & Pos : Neg & BMP & BMP p & GSIGN & GSIGN p \\
\hline$(-2 \ldots 2)$ & -0.0238 & $7: 18$ & -2.9066 & 0.0037 & -1.8993 & 0.0575 \\
\hline \multicolumn{7}{c}{ Table 3 - Test results Group 1 }
\end{tabular}

To better understand the reason for this discrepancy, a manual review of the individual asset CAR was conducted. This was feasible as the sample size for this study is comparatively small. By plotting the results for Group 1 (Figure 3), it was found that the non-significant result in the GSIGN test is likely due to a strong outlier (U:WYN, $-22 \%$ ). 


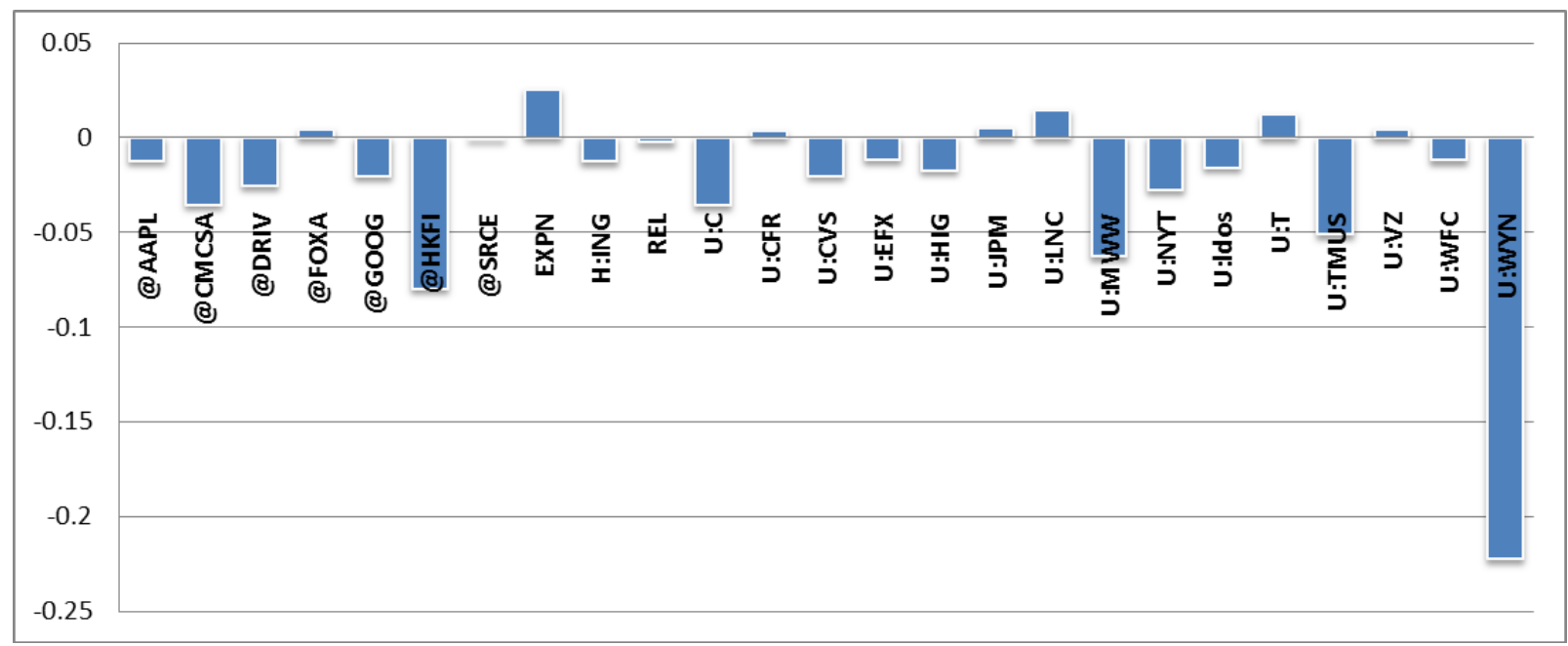

Figure 3 - Individual CAR Group 1

As normality of the data is not warrant, the strong significance level in the parametric test should be considered of limited relevance. Although non-parametric tests are not immune to outliers (Zimmerman, 1994) taking into consideration that the non-parametric tests approaches significance level, rejection of $\mathrm{H}_{1}$ seems likely.

Calculations were repeated for the events in Group 2 using the same approach as above. The results of Group 2 are noticeably different to the observations of Group 1 showing a CAAR of only $-0.16 \%$ with a flat AAR distribution around the event date as illustrated in Figure 4.

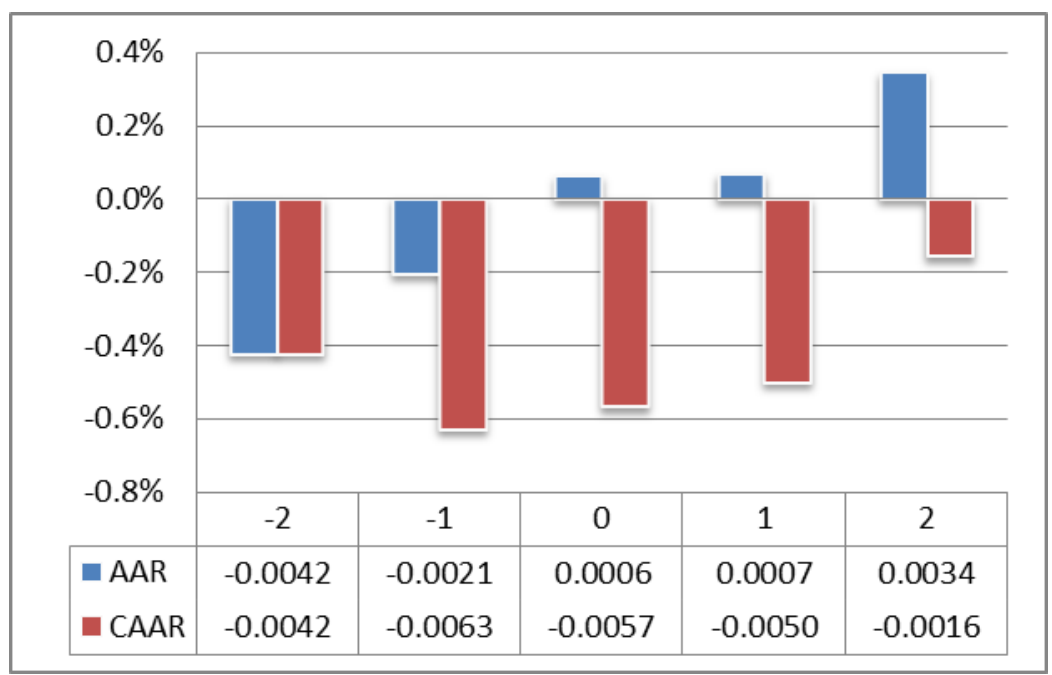

Figure 4 - Group 2 event impact

Looking at the statistical tests, there was no indication of significance in the results for Group 2, either for the parametric or non-parametric methods.

\begin{tabular}{|ccccccc|}
\hline $\begin{array}{c}\text { Event } \\
\text { window }\end{array}$ & CAAR & Pos : Neg & BMP & BMP p & GSIGN & GSIGN p \\
\hline$(-2 \ldots 2)$ & -0.0016 & $9: 16$ & 0.0213 & 0.983 & -1.1244 & 0.2608 \\
\hline \multicolumn{7}{c}{ Table 4 -Test results Group 2 } \\
\hline
\end{tabular}


As an additional verification, the individual CAR for each asset in the group was plotted. Figure 5 shows no outliers and exhibits a balanced dataset for Group 2.

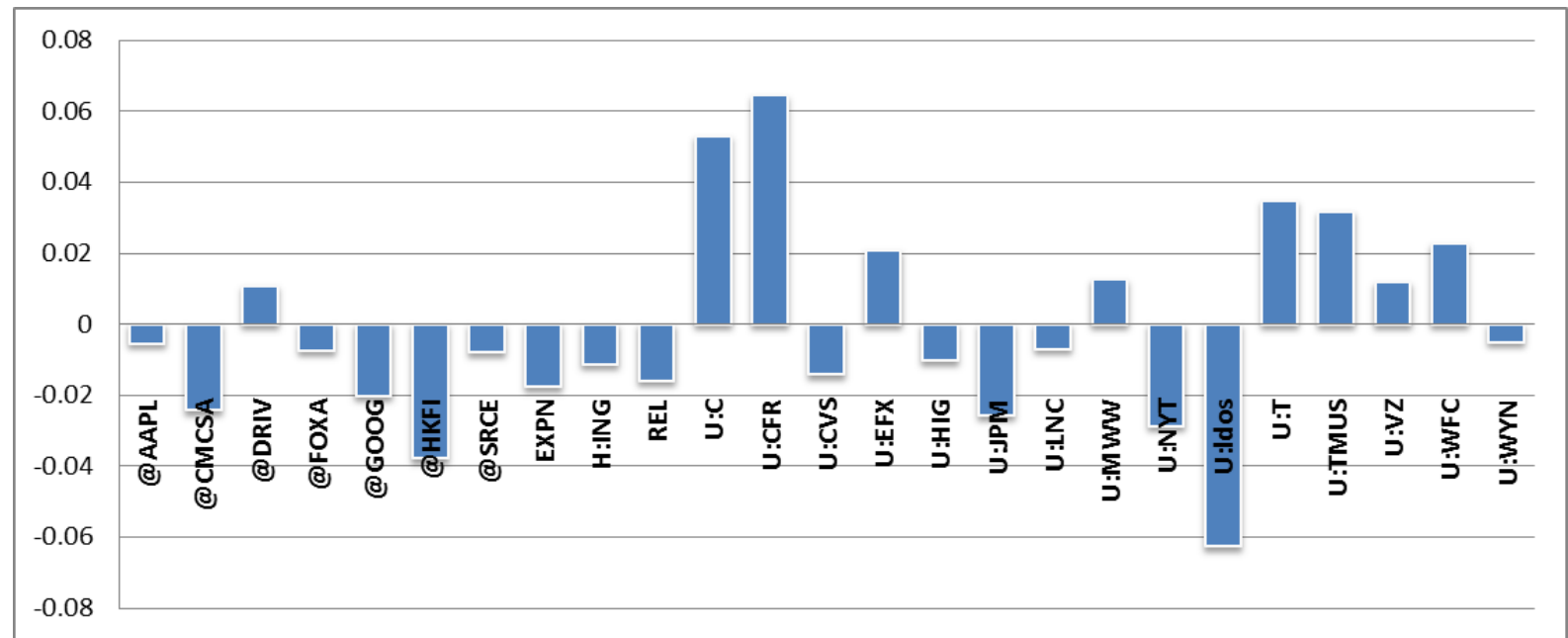

Figure 5 - Individual CAR Group 2

The results for Group 2 show no statistical significance on any indicator, accordingly, rejection of $\mathrm{H}_{1}$ for this group cannot be concluded.

In addition to the calculations for each event group, the combined event data was analysed to obtain the results for the overall event pool. Taking all events into consideration, the CAAR showed a return of $-1.27 \%$ carried by a $16: 34$ positive:negative ratio.

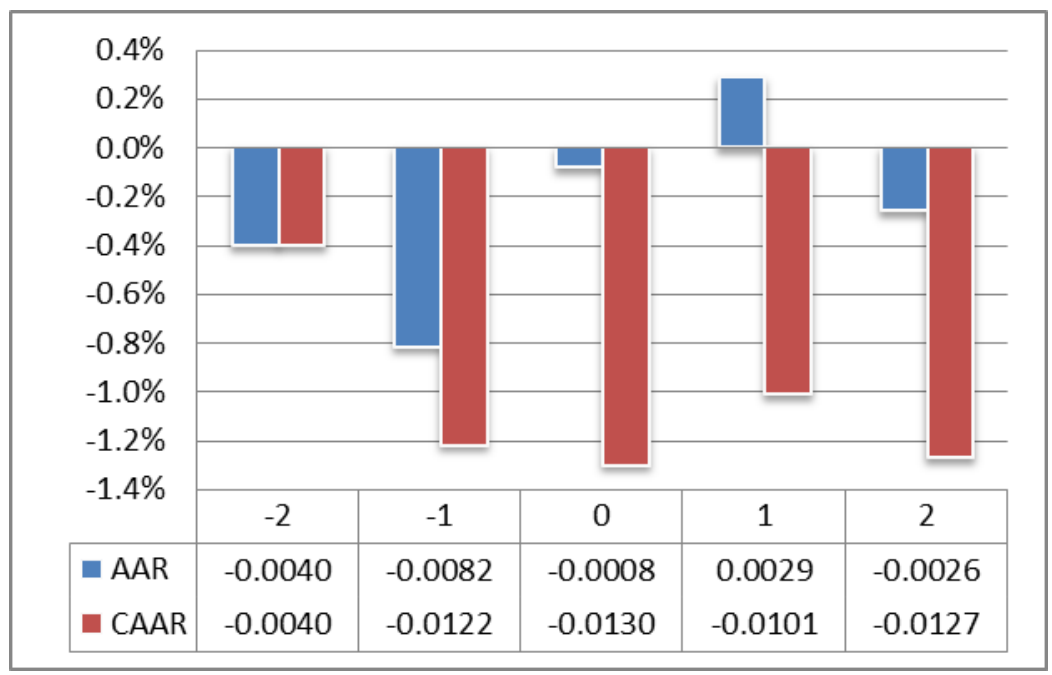

Figure 6 - Event impact for the complete event pool

The parametric test showed little significance and suffered from non-normality in the dataset (as Group 1 data is a subset and thus carries the same outlier issue). The GSIGN test results are well within the critical region, however. 


\begin{tabular}{|lcrcrrr|}
\hline Event window & CAAR & Pos : Neg & BMP & BMP $p$ & GSIGN & GSIGN $p$ \\
\hline$(-2 \ldots 2)$ & -0.0127 & $16: 34$ & -1.3943 & 0.1632 & -2.138 & 0.0325 \\
\hline
\end{tabular}

Table 5 - Test results complete event pool

The CAR for each individual asset in each group was plotted as seen in Figure 7 showing the reaction for each organization in the sample pool to both events in an overlay illustration.

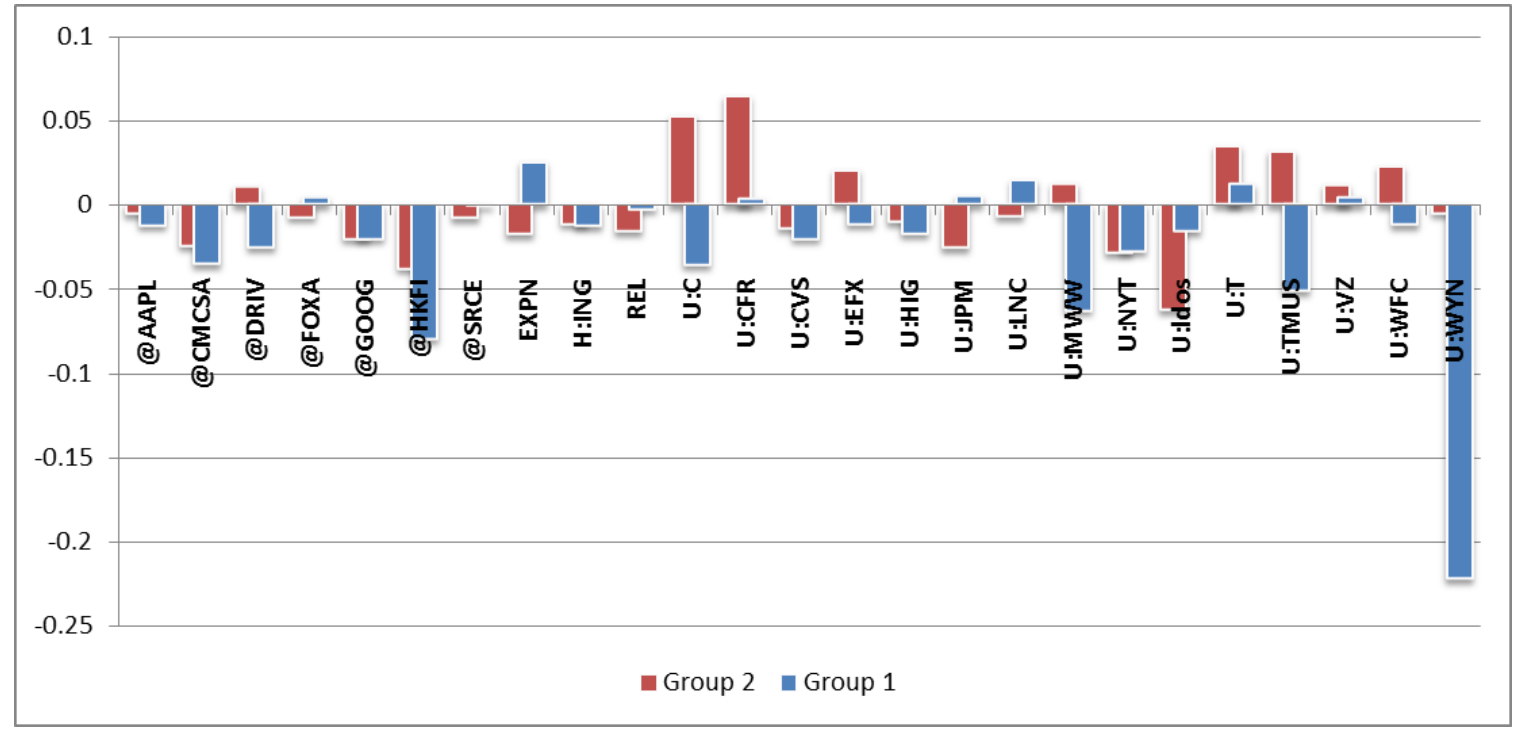

Figure 7 - Combined CAR for the event pool

Considering the outlier problem, and subsequently the implications from parametric testing, the results of the non-parametric tests are given priority for reaching a conclusion on $\mathrm{H}_{1}$. Taking all 50 events into consideration, we identified a negative effect $(-1.27 \%)$ over the observed event window which is considered significant with a $\mathrm{p}$ value $<0.05$ (Pearson, 1900) as shown by the non-parametric test.

To answer the question posed by $\mathrm{H}_{2}$, the individual CAR for each asset in Group 1 are compared with those of Group 2. The intention is to understand if cumulative abnormal returns for each asset are significantly different between the first measured breach event (Group 1) and the subsequent breach event (Group 2). A visual comparison of the individual CAR provided no clear indication albeit Group 1 appeared to show a slightly stronger negative reaction. 


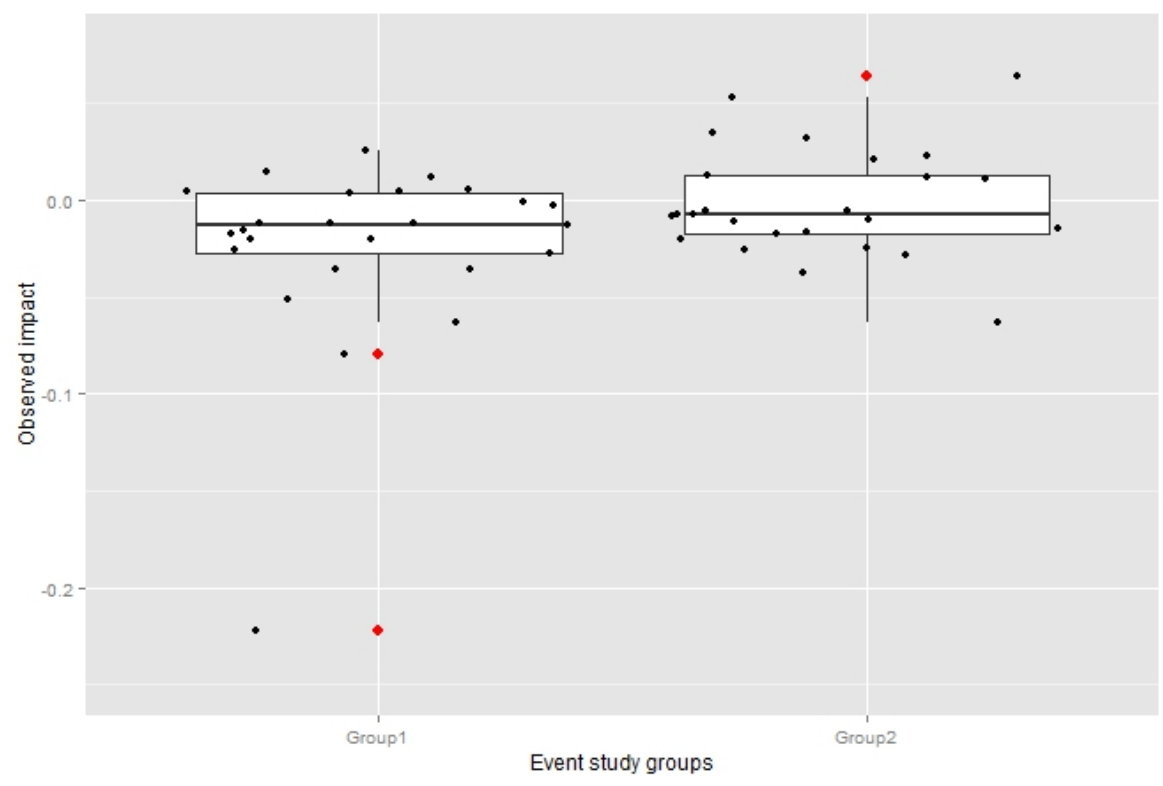

Figure 8 - Box plot of individual CAR between groups

Comparing the CAAR for each group as calculated in the previous section, Group 1 showed a considerable stronger negative return (Group $1-2.38 \%$, Group $2-0.16 \%$ ); However, as noted earlier, this was driven by an outlier.

To better understand the impact of the identified outlier, we temporarily removed the outlier in Group 1 from the dataset. This resulted in a negative return of $1.55 \%$. It also showed a tendency to normality, yet, indicated that there was still a noticeably stronger negative reaction for Group 1 .

As discussed earlier, data in Group 1 is not normally distributed which reduces the usefulness of parametric testing. To understand the extent to which the data is non-normal, a Shapiro-Wilk (Shapiro and Wilk, 1965) test was applied to both groups. Results are shown in Table 6.

\begin{tabular}{lrr} 
SW test & Group 1 & Group 2 \\
\hline W & 0.671252696 & 0.963874 \\
p-value & $3.06201 \mathrm{E}-06$ & 0.496879 \\
alpha & 0.05 & 0.05 \\
normal & no & yes \\
\hline \multicolumn{3}{c}{ Table 6 - Shapiro-Wilk test }
\end{tabular}

While a paired samples t-test was conducted, it was not taken into consideration. Instead, the non-parametric Wilcoxon Signed-Rank Test for Paired Samples (Wilcoxon, 1945) was used to assess significance of differences in the dataset. With a $\mathrm{p}$ value of 0.074 on the two-tailed test, we could not reject $\mathrm{H}_{2}$. 


\section{Results}

Observing the CAAR for study Group 1, we found a negative return of $2.38 \%$ aligned with the event date corresponding to a $\mathrm{p}$ value of 0.0037 using the standardized cross-sectional test as proposed by Boehmer et al. (1991). This result in the parametric test is likely driven by an outlier as described in section 4, however. The non-parametric result under generalized sign testing, on the other hand, finds significance approaching the $95 \%$ confidence level ( $p$ value $=0.0575$ ). Considering the tendency of both test results we reject $\mathrm{H}_{1}$ for this group. For Group 2, we found a CAAR that is very close to zero $(-0.16 \%)$ with consequently insignificant statistical results. Applying the model to the whole event pool, we found a negative CAAR of $1.27 \%$ that showed significance on the non-parametric test $(\mathrm{p}$ value $=0.0325)$ but not on the parametric test ( $\mathrm{p}$ value $=0.1632$ ). The study shows a strong tendency towards rejection of $\mathrm{H}_{1}$.

$\mathrm{H}_{2}$ is addressed by comparing the cumulative abnormal residuals between group one and two. Utilizing a Shapiro-Wilk test, we found data in Group 1 to be non-normal suggesting the use of a non-parametric test, such as Wilcoxon Signed-Rank, to conduct a statistical evaluation. Although the difference in absolute CAAR between Group 1 and Group 2 seemed to indicate that there is ground to reject $\mathrm{H}_{2}$, the statistical test did not support this initial notion. The Wilcoxon SignedRank test showed only marginal significance ( $\mathrm{p}$ value $=0.074$ ) on the two-tailed test, which is considered insufficient to reject $\mathrm{H}_{2}$ in context of this study. Or in other words, we found merely weak statistical evidence in this study that the market reacts differently to a subsequent breach event affecting the same organisation.

\section{Threats to validity and study limitations}

Based on the results of this study, we weakly conclude that there is an impact on the stock price of organisations that suffer from a publicly announced information security breach. The weakness in explanatory power is driven by several limitations inherent to event studies in general and this study in particular. Event study methodology relies on the assumption of an efficient market with rational players. In reality, this assumption does not necessarily hold considering efficiency (Malkiel, 2003) or rationality (deBondt and Thaler, 1985, Dichev and Janes, 2003). Kothari and Warner (2004) caution that predictions about securities' unconditional expected returns are imprecise, consequently the greater the imprecision in the predicted returns (error factor) the lesser the explanatory power any model has which is based on it. Particularly for short-term event studies, knowing the precise event date is of crucial importance. Uncertainty about the exact event date is an issue and a compromise between availability of data and quality of the dataset had to be made. Yet, even if the precise date of the event is known, there is still uncertainty around the speed of information dissemination across market participants as previously discussed. Further limitations stem from potential unrelated event correlation (confounding events) around the event dates, which are difficult to reliably identify ex post. In addition, there are noteworthy challenges specific to RQ2 affecting the time window between the first measured breach event and the second measured breach event. Following such an event organisations not only work on mitigation of the original breach cause but also invest in improvements and trust building initiatives such as replacing key executive positions (Chief Executive Officer, Chief Technology Officer, Chief Security Officer, etc.). The potential influence of such activities on the subsequent breach event has not been considered in this study. 
These potential issues, as well as the outlier in the sample pool, are magnified by the small sample size available for this study reducing the significance of statistical tests.

In terms of this study, the results can be seen as indication of impact tendency. While there were merely weakly explanatory results applying strict methodology, a tendency to significance could be identified, particularly if we only consider one tailed testing results.

\section{Conclusion}

Understanding the role of information security in context of the economic well-being of an organisation is a difficult yet important proposition (Anderson, 2001, Gordon and Loeb, 2002). Research in this area has been looking at existing approaches used by economists and applied promising methods in an attempt to answer questions on the economic value of information security. One such approach is the event study methodology as applied in this work. As discussed in section 1, we rely on the assumption of an efficient market to measure potential abnormal effects caused by an information security relevant event. In this study, we set to answer two main research questions:

- RQ1: Do publicly reported information security breaches impact stock prices of affected organisations?

- RQ2: Is there a difference in stock price impact, compared to a previous breach, if organisations experience a subsequent information security breach event?

To answer these questions, we retrieved event data from the PRC database, filtered it for relevancy, and matched the resulting 50 events with corresponding stock price and index time series information to conduct a market model event study.

The data were split into two groups. For the first group, consisting of each organisations earlier breach event, we found an indication of significant negative reaction (parametric $\mathrm{p}$ value $=$ 0.0037, non-parametric $\mathrm{p}$ value $=0.0575$ ). For the second group containing the latter events, there was no significant reaction (parametric $p$ value $=0.98$, non-parametric $p$ value $=0.26$ ). The combined event pool shows a tendency to significance based on the parametric test ( $\mathrm{p}$ value $=$ 0.1632 ) and non-parametric test ( $p$ value $=0.0325$ ) findings.

Considering the limitations discussed, for RQ1, we weakly conclude that information security events have an impact on the economic well being of organisations, as expressed by the corresponding stock price based on the parameters of this study. For RQ2, we did observe a difference in reaction between the two study groups with a non-parametric test $p$ value approaching significance (0.074).

Finally, we can conclude that the selected approach and methodology to evaluate economic impact of information security events is promising. If some of the limitations discussed can be addressed, such as the sample size and the precise identification of event dates, the methodology can provide valuable input to support economic decision making within enterprise risk management programs. This indeed might become possible in the near future where it is expected that public information on data breaches will become more widely available and more detailed as laws and regulations become more explicit on the reporting of such incidents (Dipietro, 2013, Smedinghoff, 2006). This will make more quality data available upon which the methodology can be applied. The larger sample size will allow more sophisticated analysis to be conducted and help draw more reliable conclusions. 


\section{Acknowledgments}

We would like to thank the anonymous reviewers for their valuable input.

\section{References}

ANDERSON, R. Why information security is hard - An economic perspective. 17th Annual Computer Security Applications Conference, Proceedings, 2001 Los Alamitos. IEEE Computer Society, 358-365.

ANDOH-BAIDOO, F. K., AMOAKO-GYAMPAH, K. \& OSEI-BRYSON, K. M. 2010. How Internet Security Breaches Harm Market Value. Security \& Privacy, IEEE, 8, 36-42.

BOEHMER, E., MASUMECI, J. \& POULSEN, A. B. 1991. Event-study methodology under conditions of event-induced variance. Journal of Financial Economics, 30, 253-272.

BROWN, S. J. \& WARNER, J. B. 1985. USING DAILY STOCK RETURNS - THE CASE OF EVENT STUDIES. Journal of Financial Economics, 14, 3-31.

CAMPBELL, K., GORDON, L. A., LOEB, M. P. \& LEI, Z. 2003. The economic cost of publicly announced information security breaches: empirical evidence from the stock market. Journal of Computer Security, 11, 431-48.

CAVUSOGLU, H., MISHRA, B. \& RAGHUNATHAN, S. 2004. The effect of Internet security breach announcements on market value: Capital market reactions for breached firms and Internet security developers. International Journal of Electronic Commerce, 9, 69-104.

CORRADO, C. J. 1989. A nonparametric test for abnormal security-price performance in event studies. Journal of Financial Economics, 23, 385-395.

COWAN, A. R. 1992. Nonparametric event study tests. Review of Quantitative Finance and Accounting, 2, 343-358.

CUTLER, D. M., POTERBA, J. M. \& SUMMERS, L. H. 1989. WHAT MOVES STOCKPRICES. Journal of Portfolio Management, 15, 4-12.

DEBONDT, W. F. M. \& THALER, R. 1985. Does the Stock Market Overreact? The Journal of Finance, 40, 793-805.

DICHEV, I. D. \& JANES, T. D. 2003. Lunar cycle effects in stock returns. The Journal of Private Equity, 6, 8-29.

DIPIETRO, B. 2013. International Data Breach Laws Are All Over The Map [Online]. Available: http://blogs.wsj.com/riskandcompliance/2013/09/24/international-data-breachlaws-are-all-over-the-map/ [Accessed November 23rd 2013].

DUSO, T., GUGLER, K. \& YURTOGLU, B. 2010. Is the event study methodology useful for merger analysis? A comparison of stock market and accounting data. International Review of Law and Economics, 30, 186-192.

DYCKMAN, T., PHILBRICK, D. \& STEPHAN, J. 1984. A Comparison of Event Study Methodologies Using Daily Stock Returns: A Simulation Approach. Journal of Accounting Research, 22, 1-30.

FAMA, E. F. 1970. EFFICIENT CAPITAL MARKETS - REVIEW OF THEORY AND EMPIRICAL WORK. Journal of Finance, 25, 383-423. 
FAMA, E. F., FISHER, L., JENSEN, M. C. \& ROLL, R. 1969. The Adjustment of Stock Prices to New Information. International Economic Review, 10, 1-21.

GARG, A., CURTIS, J. \& HALPER, H. 2003. Quantifying the financial impact of IT security breaches. Information Management \& Computer Security, 11, 74-83.

GATZLAFF, K. M. \& MCCULLOUGH, K. A. 2010. The Effect of Data Breaches on Shareholder Wealth. Risk Management and Insurance Review, 13, 61-83.

GORDON, L. A. \& LOEB, M. P. 2002. RETURN ON INFORMATION SECURITY INVESTMENTS: Myths vs Realities. Strategic Finance, 84, 26-31.

GRAMA, J. 2010. Legal issues in information security, Jones \& Bartlett Publishers.

INCE, O. S. \& PORTER, R. B. 2006. INDIVIDUAL EQUITY RETURN DATA FROM THOMSON DATASTREAM: HANDLE WITH CARE! Journal of Financial Research, 29, 463-479.

INTERNATIONAL STANDARDS ORGANISATION 2014. ISO/IEC DIS 27040 (Draft). Information technology. London: BSI.

KANNAN, K., REES, J. \& SRIDHAR, S. 2007. Market reactions to information security breach announcements: An empirical analysis. International Journal of Electronic Commerce, 12, 69-91.

KOLARI, J. W. \& PYNNÖNEN, S. 2010. Event Study Testing with Cross-sectional Correlation of Abnormal Returns. Review of Financial Studies, 23, 3996-4025.

KOTHARI, S. \& WARNER, J. 2004. The econometrics of event studies. In: ECKBO, B. E. (ed.) Handbook of Corporate Finance: Empirical Corporate Finance. Amsterdam: Elsevier.

LO, A. \& MACKINLAY, A. 1988. Stock market prices do not follow random walks: evidence from a simple specification test. Review of Financial Studies, 1, 41-66.

MACKINLAY, A. C. 1997. Event studies in economics and finance. Journal of Economic Literature, 35, 13-39.

MALKIEL, B. G. 2003. The efficient market hypothesis and its critics. Journal of Economic Perspectives, 17, 59-82.

NATIONAL INSTITUTE OF STANDARDS AND TECHNOLOGY 2012. Computer Security Incident Handling Guide. In: COMMERCE, U. S. D. O. (ed.) 2 ed. Gaithersburg.

PASSERI, P. 2013. 2013 Top 20 Breaches [Online]. Available: http://hackmageddon.com/2013/12/30/2013-top-20-breaches/ [Accessed March 7th 2014].

PATELL, J. M. 1976. Corporate Forecasts of Earnings Per Share and Stock Price Behavior: Empirical Test. Journal of Accounting Research, 14, 246-276.

PEARSON, K. 1900. X. On the criterion that a given system of deviations from the probable in the case of a correlated system of variables is such that it can be reasonably supposed to have arisen from random sampling. Philosophical Magazine Series 5, 50, 157-175.

PONEMON INSTITUTE 2014. Cost of Data Breach Study. Michigan: Ponemon Institute LLC.

SCHOLES, M. \& WILLIAMS, J. 1977. Estimating betas from nonsynchronous data. Journal of Financial Economics, 5, 309-327.

SHAPIRO, S. S. \& WILK, M. B. 1965. An Analysis of Variance Test for Normality (Complete Samples). Biometrika, 52, 591-611.

SMEDINGHOFF, T. J. 2006. Where we're Headed-New Developments and Trends in the Law of Information Security. Wildman Harrold News \& Publications [Online]. Available: http://www.edwardswildman.com/Files/Publication/867dcafd-bdae-4c33-affe68ea2ad688c0/Presentation/PublicationAttachment/2e55edad-c12b-4e47-8df8- 
e31faee30d1b/Where We're Headed_-

New_Developments_and_Trends_in the_Law_of_Information_Securit.pdf [Accessed 2013-11-20].

TELANG, R. \& WATTAL, S. 2007. An empirical analysis of the impact of software vulnerability announcements on firm stock price. IEEE Transactions on Software Engineering, 33, 544-557.

WANG, T., REES, J. \& KANNAN, K. 2007. Reading the Disclosures with New Eyes: Bridging the Gap between Information Security Disclosures and Incidents. Seventh Workshop on the Economics of Information Security. Hanover, NH.

WIDUP, S. 2012. Closing the Vault Door [Online]. Available: http://theleakingvault.com/closing-the-vault-door [Accessed November 2nd 2013].

WILCOXON, F. 1945. Individual Comparisons by Ranking Methods. Biometrics Bulletin, 1, 8083.

YAYLA, A. A. \& HU, Q. 2011. The impact of information security events on the stock value of firms: the effect of contingency factors. Journal of Information Technology, 26, 60-77.

ZIMMERMAN, D. W. 1994. A Note on the Influence of Outliers on Parametric and Nonparametric Tests. The Journal of General Psychology, 121, 391-401. 


\section{Appendix A}

List of organisation in the event study with business categories as provided by Thomson Reuters Business Classification.

\begin{tabular}{|c|c|c|c|c|c|}
\hline Organisation & TRBC L1 & TRBC L2 & TRBC L3 & TRBC L4 & TRBC L5 \\
\hline APPLE INCO. & Technology & Technology Equipment & $\begin{array}{l}\text { Computers, Phones \& Household } \\
\text { Electronics }\end{array}$ & Computer Hardware & Computer Hardware - NEC \\
\hline COMCAST CORP. & $\begin{array}{l}\text { Telecommunications } \\
\text { Services }\end{array}$ & $\begin{array}{l}\text { Telecommunications } \\
\text { Services }\end{array}$ & Telecommunications Services & $\begin{array}{l}\text { Integrated Telecommunications } \\
\text { Services }\end{array}$ & $\begin{array}{l}\text { Integrated Telecommunications } \\
\text { Services - NEC }\end{array}$ \\
\hline DIGITAL RIVER INCO. & Technology & Technology Equipment & $\begin{array}{l}\text { Computers, Phones \& Household } \\
\text { Electronics }\end{array}$ & Computer Hardware & Computer Hardware - NEC \\
\hline $\begin{array}{l}\text { TWENTY-FIRST } \\
\text { CENTURY FOX }\end{array}$ & Consumer Cyclicals & $\begin{array}{l}\text { Cyclical } \\
\text { Services }\end{array}$ & Media \& Publishing & Entertainment Production & Entertainment Production - NEC \\
\hline GOOGLE INCO. & Technology & Software \& IT Services & Software \& IT Services & Internet Services & Search Engines \\
\hline $\begin{array}{l}\text { HANCOCK FABRICS } \\
\text { INCO. }\end{array}$ & Consumer Cyclicals & $\begin{array}{l}\text { Cyclical } \\
\text { Products }\end{array}$ & Textiles \& Apparel & Textiles \& Leather Goods & Textiles \& Leather Goods - NEC \\
\hline 1ST SOURCE CORP. & Financials & $\begin{array}{l}\text { Banking \& Investment } \\
\text { Services }\end{array}$ & Banking Services & Banks & Commercial Banks \\
\hline EXPERIAN PLC. & Industrials & $\begin{array}{l}\text { Industrial \& Commercial } \\
\text { Services }\end{array}$ & $\begin{array}{l}\begin{array}{l}\text { Professional \& Commercial } \\
\text { Services }\end{array} \\
\end{array}$ & $\begin{array}{l}\text { Professional } \\
\text { Services }\end{array}$ & Financial Information Providers \\
\hline ING GROEP NV & Financials & Insurance & Insurance & Life \& Health Insurance & Life \& Health Insurance - NEC \\
\hline REED ELSEVIER PLC. & Industrials & $\begin{array}{l}\text { Industrial \& Commercial } \\
\text { Services }\end{array}$ & $\begin{array}{l}\text { Professional \& Commercial } \\
\text { Services }\end{array}$ & $\begin{array}{l}\text { Professional Information } \\
\text { Services }\end{array}$ & Journals \& Scholarly Research \\
\hline CITIGROUP INCO. & Financials & $\begin{array}{l}\text { Banking \& Investment } \\
\text { Services }\end{array}$ & Banking Services & Banks & Banks - NEC \\
\hline $\begin{array}{l}\text { CULLEN FO.BANKERS } \\
\text { INCO. }\end{array}$ & Financials & $\begin{array}{l}\text { Banking \& Investment } \\
\text { Services }\end{array}$ & Banking Services & Banks & Banks - NEC \\
\hline CVS CAREMARK CORP. & $\begin{array}{l}\text { Consumer } \\
\text { Cyclicals }\end{array}$ & Food \& Drug Retailing & Food \& Drug Retailing & Drug Retailers & Drug Retailers - NEC \\
\hline EQUIFAX INCO. & Industrials & $\begin{array}{l}\text { Industrial \& Commercial } \\
\text { Services }\end{array}$ & $\begin{array}{l}\text { Professional \& Commercial } \\
\text { Services }\end{array}$ & $\begin{array}{l}\text { Professional } \\
\text { Services }\end{array}$ & $\begin{array}{l}\text { Professional Information Services } \\
\text { NEC }\end{array}$ \\
\hline $\begin{array}{l}\text { THE } \\
\text { FNSR.GPIN. }\end{array}$ & Financials & Insurance & Insurance & Multiline Insurance \& Brokers & $\begin{array}{l}\text { Multiline Insurance \& Brokers } \\
\text { NEC }\end{array}$ \\
\hline $\begin{array}{l}\text { JP MORGAN CHASE \& } \\
\text { CO. }\end{array}$ & Financials & $\begin{array}{l}\text { Banking \& Investment } \\
\text { Services }\end{array}$ & Banking Services & 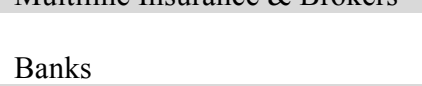 & Banks - NEC \\
\hline LINCOLN NAT.CORP. & Financials & Insurance & Insurance & Life \& Health Insurance & Life \& Health Insurance - NEC \\
\hline $\begin{array}{l}\text { MONSTER WORLDWIDE } \\
\text { INCO. }\end{array}$ & Industrials & $\begin{array}{l}\text { Industrial \& Commercial } \\
\text { Services }\end{array}$ & $\begin{array}{l}\begin{array}{l}\text { Professional \& Commercial } \\
\text { Services }\end{array} \\
\end{array}$ & Employment Services & Executive Search Services \\
\hline NEW YORK TIMES CO. & Consumer Cyclicals & $\begin{array}{l}\text { Cyclical } \\
\text { Services }\end{array}$ & Media \& Publishing & Consumer Publishing & Consumer Publishing - NEC \\
\hline $\begin{array}{l}\text { LEIDOS HOLDINGS } \\
\text { INCO. }\end{array}$ & Technology & Software \& IT Services & Software \& IT Services & IT Services \& Consulting & IT Services \& Consulting - NEC \\
\hline & Telecommunications & Telecommunications & & Wireless Telecommunications & Wireless Telecommunications \\
\hline
\end{tabular}




\section{COMMUNICATIONS}

WELLS FARGO \& CO.

WYNDHAM

WORLDWIDE CORP.
Services

Banking

Services

Cyclical

Services
\& Investment

Consumer
Consumer Cyclicals
Services

Banks
Services - NEC

Banks - NEC

Hotels, Motels \& Cruise Lines - 


\section{Appendix B}

This table shows each event window test result calculated for each group. The event window considered for this paper $(-2,2)$ has been marked in grey for each group. Critical region findings ( $\mathrm{p}$ value $<=0.05$ ) have been highlighted as well.

\begin{tabular}{|c|c|c|c|c|c|c|c|c|c|c|c|c|c|c|c|}
\hline & Date & CAAR & Pos: Neg & $\mathrm{t}$-Test time-series & Prob. & t-Test cross-sectional & Prob. & Patell Z & Prob. & Boehmer et al. & Prob. & Corrado Rank & Prob. & Sign Test & Prob. \\
\hline \multicolumn{16}{|l|}{ Group 1} \\
\hline 1 & $(-2 \ldots 2)$ & -0.0238 & $7: 18$ & -2.0969 & 0.036 & -2.4845 & 0.013 & -1.7782 & 0.0754 & -2.9066 & 0.0037 & -2.219 & 0.0265 & -1.8993 & 0.0575 \\
\hline 1 & $(-2 \ldots 0)$ & -0.0203 & $7: 18$ & -2.3077 & 0.021 & -1.8898 & 0.0588 & -1.8947 & 0.0581 & -2.6367 & 0.0084 & -1.8885 & 0.059 & -1.8993 & 0.0575 \\
\hline 1 & $(-1 \ldots 1)$ & -0.0114 & 11:14 & -1.2948 & 0.1954 & -1.9092 & 0.0562 & -0.9271 & 0.3539 & -1.6479 & 0.0994 & -0.8774 & 0.3803 & -0.2963 & 0.767 \\
\hline 1 & $(-1 \ldots 0)$ & -0.0165 & $10: 15$ & -2.2967 & 0.0216 & -1.4211 & 0.1553 & -1.5708 & 0.1162 & -1.8989 & 0.0576 & -1.4402 & 0.1498 & -0.6971 & 0.4857 \\
\hline 1 & $(0 \ldots 0)$ & -0.0022 & $10: 15$ & -0.4412 & 0.6591 & -1.0857 & 0.2776 & -0.359 & 0.7196 & -0.7612 & 0.4466 & -0.4568 & 0.6478 & -0.6971 & 0.4857 \\
\hline 1 & $(0 \ldots 1)$ & 0.0029 & $11: 14$ & 0.3989 & 0.6899 & 0.3894 & 0.697 & 0.1815 & 0.856 & 0.2807 & 0.7789 & 0.0426 & 0.966 & -0.2963 & 0.767 \\
\hline \multicolumn{16}{|l|}{ Group 2} \\
\hline 2 & $(-2 \ldots 2)$ & -0.0016 & 9:16 & -0.1577 & 0.8747 & -0.2767 & 0.782 & 0.0227 & 0.9819 & 0.0213 & 0.983 & 0.0274 & 0.9782 & -1.1244 & 0.2608 \\
\hline 2 & $(-2 \ldots 1)$ & -0.005 & $10: 15$ & -0.5601 & 0.5754 & -0.9685 & 0.3328 & -0.5036 & 0.6145 & -0.4451 & 0.6562 & -0.3886 & 0.6976 & -0.7238 & 0.4692 \\
\hline 2 & $(-2 \ldots 0)$ & -0.0057 & 11:14 & -0.733 & 0.4636 & -1.2464 & 0.2126 & -0.8033 & 0.4218 & -0.6786 & 0.4974 & -0.7437 & 0.457 & -0.3232 & 0.7466 \\
\hline 2 & $(-1 \ldots 0)$ & -0.0014 & $14: 11$ & -0.2288 & 0.8191 & -0.3337 & 0.7386 & -0.7601 & 0.4472 & -0.6704 & 0.5026 & -0.3745 & 0.708 & 0.8787 & 0.3796 \\
\hline 2 & $(0 \ldots 0)$ & 0.0006 & $13: 12$ & 0.1361 & 0.8917 & 0.1497 & 0.881 & -0.2323 & 0.8163 & -0.2261 & 0.8211 & 0.0506 & 0.9597 & 0.478 & 0.6326 \\
\hline 2 & $(0 \ldots 1)$ & 0.0013 & $14: 11$ & 0.2019 & 0.84 & 0.3165 & 0.7516 & 0.1074 & 0.9145 & 0.1253 & 0.9003 & 0.3971 & 0.6913 & 0.8787 & 0.3796 \\
\hline \multicolumn{16}{|l|}{ Group all } \\
\hline All & $(-2 \ldots 2)$ & -0.0127 & $16: 34$ & -1.6773 & 0.0935 & -2.2105 & 0.0271 & -1.2414 & 0.2145 & -1.3943 & 0.1632 & -1.4204 & 0.1555 & -2.138 & 0.0325 \\
\hline All & $(-2 \ldots 1)$ & -0.0101 & $18: 32$ & -1.4925 & 0.1356 & -2.4902 & 0.0128 & -1.2987 & 0.194 & -1.4068 & 0.1595 & -1.1954 & 0.2319 & -1.5714 & 0.1161 \\
\hline All & $(-2 \ldots 0)$ & -0.013 & $18: 32$ & -2.2159 & 0.0267 & -2.2138 & 0.0268 & -1.9078 & 0.0564 & -1.9215 & 0.0547 & -1.8028 & 0.0714 & -1.5714 & 0.1161 \\
\hline All & $(-1 \ldots 1)$ & -0.0061 & $22: 28$ & -1.0378 & 0.2994 & -1.5965 & 0.1104 & -0.9376 & 0.3485 & -1.1073 & 0.2682 & -0.5783 & 0.563 & -0.4381 & 0.6613 \\
\hline All & $(-1 \ldots 0)$ & -0.009 & $24: 26: 00$ & -1.8742 & 0.0609 & -1.441 & 0.1496 & -1.6482 & 0.0993 & -1.6228 & 0.1046 & -1.2257 & 0.2203 & 0.1286 & 0.8977 \\
\hline All & $(0 \ldots 0)$ & -0.0008 & $23: 27$ & -0.241 & 0.8096 & -0.3597 & 0.7191 & -0.4181 & 0.6759 & -0.5274 & 0.5979 & -0.2576 & 0.7967 & -0.1548 & 0.877 \\
\hline All & $(0 \ldots 1)$ & 0.0021 & $25: 25: 00$ & 0.4328 & 0.6652 & 0.4985 & 0.6181 & 0.2043 & 0.8381 & 0.2632 & 0.7924 & 0.3352 & 0.7375 & 0.4119 & 0.6804 \\
\hline
\end{tabular}

We computed all event-study results using the Event Study Metrics software. 
${ }^{\mathrm{i}} \mathrm{http} / / /$ datalossdb.org/

ii http://www.privacyrights.org/data-breach

iii Data source - Thomson Reuters Datastream

${ }^{\text {iv }}$ Data source - Recorded Future (https://www.recordedfuture.com/) 